UNIVERSITY
OF DEBRECEN

FACULTY OF

HEALTH

NYÍREGYHÁZA

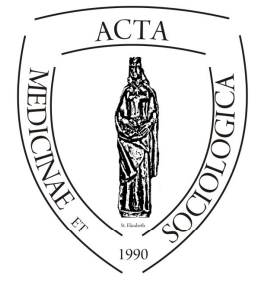

ACTA

MEDSOC

VOLUMe 3.

2013

\title{
An overview of recent social policy and services in Hungary: thoughts of a new compilation of studies
}

\author{
György Szabados \\ Ferenc Bódi, Gergely Fábián, Thomas R. Lawson (Ed.): \\ Local Organization of Social Services in Hungary \\ DOI: $10.19055 / \mathrm{ams} .2013 .4 / 11 / 8$
}

Three years after the exchange of governments and one year before the next elections in Hungary, an almost 400 hundred page collection of novel articles raised my interest. Regarding the discipline of sociology and social policy, I often manage to find books on special issues, but not a comprehensive one which would give an overall picture of what has happened in Hungary in the last ten years. Although I have Giddens (the general basic literature of the profession) and Andorka (the domestic classic) on my shelf, unfortunately, the former's research stopped before the crisis regarding the issues examined, while the latter title only includes information from shortly after the millennium, and I rarely manage to find current knowledge on specific social national issues. Thus, finding one which provides an overall view of facts seems quite difficult.

According to the editors, this compilation of articles has almost two decades of antecedents, in the framework of the project called Local Organization of Social Services, with the aim to "build a bridge among different social cultures and social politics which exist in the United States, Western Europe and the socalled transition countries of Central and Eastern Europe". With the collapsing 
of regimes in this part of Europe, significant changes occurred: the transition into democracy; the introduction of a market economy; privatization and the intention to make this process as smoothly and quickly as possible, without causing enormous disturbances in the operation in national society. A major change in the last years happened in politics, since the former minority party (Fidesz) gained a two-thirds majority in the last election and brought significant changes in numerous fields, such as the labor market, the taxation system, legislation, public administration or the field of civic organizations.

During the more than twenty transition years, we may have witnessed significant successes together with significant failures. The persevering attitude to foster the process of accession to the European Union might also be experienced up to 2004, when Hungary signed the accession treaty. Some mention this as a new time in the history of the country. We most definitely experience signs of this in reference to the accession funds, the transformation of the education system and we may also witness newly experienced symptoms, such as the appearance of poverty, regions lagging behind the heart of the country or the openness and exposure of the country to global market events.

This book was meant to be an element of a series of comparative research within a larger network in the Euro-Atlantic region, and further issues may be expected in the future on the status quo of other countries. Being one of the series, it is really about what really happened lately in the most important social fields and what is worth to know when we try to describe the social situation of the country itself.

This compilation includes 18 diverse professional articles on different fields of social issues in Hungary. The editors of the volume are Ferenc Bódi, PhD, senior research fellow of Hungarian Academy of Sciences, Prof. Gergely Fábián, $\mathrm{PhD}$, dean of University of Debrecen Faculty of Health and Prof. Thomas R. Lawson, PhD, FUAS professor and director of International programs Kent School of Social Work, University of Louisville, meaning that this book is the result of a solid international scholar research partnership.

The editors have split up the essays of this volume into three different fields. The subject of local organization of social services primarily focuses on the historic background and a more general and external approach of the social themes and thereby forms a prequel to the next, more detailed and specific issues. The subject of inequalities reveals discrepancies and tension inside the country's social system, with most of the examinations based on primary research. The last subject includes only one article which is on regional policy issues.

I would also divide the included essays into at least two main categories, those which fell into the category of secondary analysis and those which have primary research background. Many of the articles deal with the subject of minorities in Hungary, the difference in living conditions, way of life or the tolerance and 
attitude of the majority of society against them. In the sequence of the article, I will attempt to summarize the most important features of each of them.

The starting article by Soelter and Lawson ${ }^{1}$ intends to set up a model of the evolution of the welfare state by defining stages in its development. Their private model equally incorporates history, ideology and culture, and thereby helps to account for the "complexity of cross-national analyses" and significant changes on the way to becoming a welfare state. This work analyses different historic stages and relationships during Hungary's history. Their theoretical model is a conceptualization of a holistic interpretation of a welfare state. This socio-cultural approach illustrates and explains each point of interaction of the internal and the external rings of the welfare system. The research also reveals the special nature of the welfare system from the point of view of successive Hungarian governments. It might offer a conceptual framework that "could potentially be utilized to develop quantitative predictor factors" and be "used for a more comprehensive and accurate cross national welfare state analysis".

Bódi, in his own article, ${ }^{2}$ deals with the development of the Hungarian welfare system. Starting out from the Habsburg monarchy, such important issues were discussed as worker protection, pension, health insurance and poverty relief and after major typical, determinant elements of the social regime, the centralization, the effect of the governing ideology and the natures of the economy were considered. Regarding the post-socialism events, he tries to deal with effects of the legacy and such novel phenomena of the new era as the changing structure of society, the affiliated social expenditures, employment and unemployment, the changing education system, the state of the health care system, lifestyle and social deviance, social anomy. This article is a good introduction and a comprehensive essay to understanding the knowledge and information of the contributions following it in the volume.

It is no wonder that Hungary faces the same modernization side effects as all western societies. Bódi-Bódi ${ }^{3}$ focused their attention on one of the most urgent issues of modern society: demographic trends and problems. They approach this issue from the changes following World War II, listing all the important moments and political interventions of socialist social policy. One of the main problems after the millennium they refer to is that more money is spent presently than can be afforded and too little is spent on the future. The most urgent issues are related to education, its financing and the number of students, the need for more

\footnotetext{
${ }^{1}$ Eric R. Soelter - Thomas R. Lawson - A socio-cultural model of the evolution of the welfare state

${ }^{2}$ Ferenc Bódi - The development of the welfare system in Hungary

${ }^{3}$ Ferenc Bódi - Mátyás Bódi - The decrease of population, the vicious circle of poverty and development model
} 
workplaces (the labor market indicators are improving, but their explanations are not unequivocal), the division of the country itself regarding living conditions and economic potential. The less developed regions must also meet the expectations of "creative capital" to contribute to its social and economic sustainability. Unfortunately, the north-eastern parts of the country regenerate its special problems and cannot fight effectively the upcoming endangering phenomena: the high ratio of active aged people living on social benefits, the massive level of undereducated with the accompanying unemployment, the poor living conditions and the social and territorial separation of social layers. The authors refer to social erosion in these peripheral regions where, owing to a vicious circle of diverse events, life itself becomes degraded. Possible solutions for development include the increase in the level of education, to foster the $\mathrm{R}+\mathrm{D}$ sector and to put more emphasis on rural areas in policy.

Bódi and Bódi, in their subsequent essay, ${ }^{4}$ discuss the diverse dimensions of the voters and the elections after the transition into democracy. Only few researchers have dealt with this subject lately in a spatial dimension, although this is one of the most practical and empirical topics of the political and social sciences. This article aims to "uncover the social background of the phenomena of voting, in essence what makes people vote". Their one major finding is "voter turnout has a spatial feature that can be described year after year due to its spatial regulatory". The authors have identified the municipality-related connections and the regional features during the period between 1990-2010. Hungarian society is characterized by its duality; long term rural-urban division may be experienced. The authors tried to identify further trends on voter attitudes, such as local deficits and civic duties, and have revealed a rationalityrelated feature of the Hungarian voter.

Fónai, in his essay, ${ }^{5}$ analyzes two major phenomena in Hungary, the municipality system and local community specific issues, problems of special communities, the Roma people. The author intends to compare essences of four surveys on the "potential impacts of community problems and residential needs on local politics". He highlighted the most important personal and community problems and their evaluation from different aspects. He pointed out the difference between the Roma and non-Roma populations, since "the non-Roma population has a rather different estimate of problems". The author seeks answers for his five hypotheses on this subject and emphasizes that only little comparative empirical research has been carried out on these issues.

\footnotetext{
${ }^{4}$ Ferenc Bódi - Mátyás Bódi - Where are the voters?

${ }^{5}$ Mihály Fónai - potential impacts of community problems and residential needs on local politics
} 
Bódi and Giczey, in the framework of their study, ${ }^{6}$ examine a pressing social issue throughout the history of the country, that of migration. The article guides the reader through all of the most important events, focusing on diverse migration waves, emigration to America, the effects of the World Wars and the situation today. A specific issue of the low level of Hungarian emigrants to the West is also negotiated and the authors attempt to explain the reasons as to why Hungarians are much less active in working abroad compared to the PolishRomanian-Slovakian trio. There is very little true entrepreneurship in Hungary, and there is a level of compulsory entrepreneurs who are "at the mercy of certain graces". The authors conducted a private examination of student attitudes and opinions of social tolerance toward immigrants, and it seems that a relatively high level of intolerance may be experienced toward the Roma people. As a whole, the authors have found that "the country, despite its traditions, has become more closed during the past two decades ".

Bódi $^{7}$ in his essay deals with the complex issues of the crisis of a country. "Crisis is a malfunctioning of the society on four areas: economic structure, financial system, political legitimacy, and culture and morality". The author has tried to find reasons for the current situation by going through the events of the past fifty years. Hungary is the "country of the benefited-households mostly depending on pensions and pension-like benefits. According to a private survey, four-tenth in the country's population said the pensions are the main income of their households. The author examined different features of those living on pensions and also raised urgent problems, mainly regarding rural areas.

Bódi and Horváth, in their article, ${ }^{8}$ focused on the two most important issues of current times. There is "a welfare slope regarding accessibility of basic health care has became even steeper, as penetration of care has improved in urban areas but deteriorated in rural areas". There is a silent split in the country and, in their first chapters, they focus on the differences between municipality types in basic public health services. They also deal with the situation of public benefit employees and the natures of this sector between 2003-2009. Some rural areas are seriously endangered, since income generation is poor and "many are not able or willing to be employed", there is a high rate of low qualified, uneducated and long term unemployed people, which seems to break off in numerous dimensions from the more developed parts of the country.

\footnotetext{
${ }^{6}$ Ferenc Bódi - Péter Giczey - Migration processes in modern Hungary and today

${ }^{7}$ Ferenc Bódi - The elements of the complex crisis, and its influences ont he rural societies-the historical background of the disadvantageous situation

${ }^{8}$ Ferenc Bódi - Zsuzsanna Horváth - Shadows and ghosts in rural welfare system
} 
Obádovics et al. ${ }^{9}$ deal with the territorial inequalities of the economic and welfare situation in rural Hungary. Territorial, social, welfare and economic inequalities seem to have increased in recent years. The article focuses on different issues of this inequality: incomes, poverty, employment, and especially poverty They have identified a "significant association between poverty index and income gap indicators, low income discrepancies were found in the majority of poor micro regions", and, regarding the majority of rich micro-regions, there were high income inequalities.

Fábián and Takács ${ }^{10}$ introduce an empirical study finding, in which they have tried to reveal the relationship between poverty and other factors, such as employment and social support. They also analyzed opinions on social benefits. They have revealed that the "impact of financial crisis on the citizen's income has been rather unfavorable". Polarization in many fields may be experienced and also involves a "declining standard of living for the middle classes".

Fónai and Vitá ${ }^{11}$ examined the situation of the Roma communes in a small city in a crisis region in Hungary, where the ratio of the Roma population is about $20-25 \%$. Segregation is present, with the Roma traditionally living separated from the non-Roma; the level of education is low, as is that of employment. The researchers examined the socio-demographic characteristics of these households, focusing specifically on education and future hopes for change regarding the Roma and education. Social security benefits and supports are the major sources of income for Roma households and there is a significant difference between Roma and non-Roma households in numerous ways; a most important one is employee income. They also accessed the way of life indicators, the judgment of the standard of services and treatment together with mental status, and they managed to identify signs of several unfavorable effects.

Fábián et al. ${ }^{12}$ raised the revealing issue of the poor and the institution and operation of usury. The authors believed that "a kind of distorted mechanism" can be recognized regarding its operation. In their examinations of interviews of inhabitants of Roma slums, they recorded basic socio-economic data, from the living conditions to the world of work, the effect of the support system and the family. The interview findings on the Roma stressed the importance of the neighborhood, the acquaintances in their finance of life regarding borrowing

\footnotetext{
${ }^{9}$ Csilla Obádovics - Emese Bruder - László Kulcsár - Territorial inequalities of economic and welfare situation in rural Hungary-similarities and differences

${ }^{10}$ Gergely Fábián - Péter Takács - Recession and inequalities-local findings

${ }^{11}$ Mihály Fónai - Attila Vitál - The social situation and the health status of the Hungarian and Vlach gypsy population in Tiszavasvári

${ }^{12}$ Gergely Fábián - Katalin Szoboszlai - Lajos Hüse - „Money with interest”-The institution of the usury among those living in slum-like conditions
} 
money. The research reinforced that although there is an increased police alert on this field, usury "cannot be stopped merely with the decrease of the supply, and there is not a perfect method that leads to the cessation of usury".

Bódi and Fekete ${ }^{13}$ deal with supply and demand in elementary education between 1988-2009. They examined the demographic situation and the natures of the supply side. It seems, that" the utilization of kindergarten was almost irrespective of the changes in the number in the age group and the institutions". They revealed that there were winners of the transformation of education: the towns, owing to their ability to maintain the headcount of their elementary level institutions; and potential losers: which were villages with less than a thousand inhabitants, who had to commute to access the same services. The authors admitted that "serious deficiencies of the national primary education system have not ceased during the past twenty years."

The work of Balázsi and Bódi ${ }^{14}$ examines "the characteristics and performance of schools closed between May 2006 and May 2009 ". 141 schools were closed in Hungary and another 161 schools were reduced to 4 or 6 grades. The researchers revealed the different characteristics of the closed schools and stated that there were "no relation between school reorganization and their physical conditions". They identified one difference between closed and non-closed schools: "in the case of the former it was more frequent that children commuted to other neighborhoods rather than to choose the given schools".

Fekete $^{15}$ also tries to understand the efforts of the local municipalities of the villages to save their schools. The author, in the framework of interviews, described a complex and complicated picture of different interests and aims combined with central political initiation - to decrease the number of schools and the village movements established to protect them. In addition to economic interest, schools were also examined on an emotional level, due to the fear that the village would disappear with the closure of its school. The author stresses that "changes happened without any professional assessment, only because of economic constraints".

Laki and Szabó, ${ }^{16}$ in their work, tried to highlight current attitudes of the youth of their most pressing problems, through various indicators. "Young people in different financial situations, living and consuming conditions have different views of the circle of the most serious generation problems", and Youth 2008 survey tried to identify its most important features. "There is a

\footnotetext{
${ }^{13}$ Ferenc Bódi - Attila Fekete - Changes in supply and demand in elementary education 1988-2009

${ }^{14}$ Ildikó Balázsi - Ferenc Bódi - School performance-school reorganization

${ }^{15}$ Attila Fekete - Schools at the border's edge

${ }^{16}$ László Laki - Andrea Szabó - The Hungarian world according to the young...
} 
rather worrying image of society behind where uncertain present, unplannable and unreliable future, the fear from unemployment, the chance to get into poverty are shaping the spirit, way of living and life strategies". Many of the youngsters feel they are drifting without any aims and are confused. The country did not move towards the development of a modern society, if there is among youth a shared, widespread feeling of insecurity, incalculability and that they have no real aims in life to follow.

Csoba $^{17}$ deals mostly with the events of the last twenty years in the labor market. She compares the most important features of the former regime's labor market tendencies, regulations and the changing conditions and figures since then. There is a specific focus on the effect of regulations initiated by the new government. She claims that, at present, "the private sector plays a rather small role in increasing the level of employment, and the crisis of 2008 still have an effect on the representatives of the private sector". She also concludes that "the current instruments of employment policy involving participants from the private sector are in evidence only to small degree and fall far short of both expectations and opportunities with respect to their effects at the present time".

Bódi and Fekete, ${ }^{18}$ in the last article of the compilation, deal in their work with regional policy issues. In a survey between 2009-2010, they tried to analyze political activity in relationship with location and they also revealed different status groups. They examined the groups' political effectiveness and election activity. The rural municipalities, regarding the subject of development, became dependent on application funds. According to the authors' finding, "the greatest responsibility in the development of the municipality is attributed to the mayor. The population of permanently underdeveloped places can mostly count on their closed environment". Regarding the key question of their research - what does evaluation of local politics and public life depend on: the development path of the municipalities or the status groups - there is no unifying, direct answer given by the authors.

In conclusion, I found this compilation of articles very interesting, owing to the diversity of the fields in social policy represented and the examination of current events and trends. The composition of the authors suggests that this publication goes beyond what is usually offered in a volume of conference proceedings; this publication appears to be a thorough guide to the history of the past twenty-fifty years of social affairs, while also reflecting the current state of affairs, which

\footnotetext{
${ }^{17}$ Judit Csoba - labour market changes, employment policy challenges and responses in Hungary

${ }^{18}$ Ferenc Bódi - Attila Fekete - Do it Youself sir if You do not have a servant
} 
have been exacerbated by the global economic crisis. I would recommend this research to all those interested in a country in social transition, be they scholars or students who are new to the subject of Hungarian social policy areas.

Original source:

Ferenc Bódi - Gergely Fábián - Thomas R. Lawson: Local Organization of Social Services in Hungary

Bremen, Germany Studies in Comparative Social Pedagogies and International Social Work and Social Policy, Vol.XXII. Europäischer Hochschulverlag Gmbh \& Co.KG., 2013.

\section{György Szabados}

